\title{
Solitary nasal trichoepithelioma
}

\section{Lucas Gomes Patrocinio ${ }^{1}$, Priscila Garcia Damasceno ${ }^{2}$, Tomas Gomes Patrocinio ${ }^{3}$, José Antonio Patrocinio ${ }^{4}$}

Keywords: plastic surgery, skin neoplasms, nasal neoplasms.

\section{INTRODUCTION}

Trichoepitheliomas are benign cutaneous neoplasms occurring mostly on the face, which derive from pillous follicles. ${ }^{1}$ There are two clinical presentations: a hereditary sex-linked multiple form that usually affects the face, scalp and upper thorax of young adults; and a non-hereditary solitary form that may affect any part of the body (but mostly the face) of adults. ${ }^{1}$ The diameter is rarely more than 2 to $3 \mathrm{~cm} .2$ It is an extremely rare tumor; in the literature we surveyed, there were only two cases of trichoepitheliomas involving the skin in the nose area. ${ }^{3,4}$

This paper reports a case of a solitary nasal trichoepithelioma that was removed surgically, followed by a flap rotation. We discuss the diagnostic and therapeutic aspects of this rare skin tumor.

\section{CASE REPORT}

JCM, a male patient aged 56 years, complained of a slow-growing lesion on the dorsum of the nose during the past five years. The physical examination showed a brownish nodule on the dorsum of the nose, with visible blood vessels, a fibroelastic consistency, and measuring $3.0 \times 2.5$ $\mathrm{cm}$ (Figure 1A). The initial diagnosis was a basocellular carcinoma. The nodule was resected surgically (Figure $1 \mathrm{~B}$ ) and sent to the pathology department, which described islands of basaloid cells within small cystic structures filled with laminated keratin and epithelial cells to form invaginations similar to follicular papillae. A diagnosis of trichoepithelioma was confirmed and the tumor was shown to have free margins. A nasogenian flap was used for reconstructing the nose (Figures $1 \mathrm{C}$ and 1D). The patient was monitored for 48 months with no recurrences.

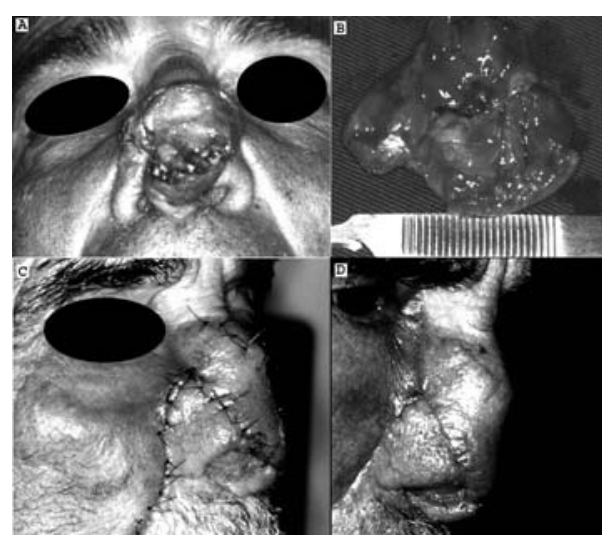

Figure 1. Pictures showing a solitary nasal trichoepithelioma (A) removed surgically $(B)$ and after reconstruction with a nasogenian flap (C e D).

\section{DISCUSSION}

Solitary trichoepitheliomas are non-hereditary benign trichogenic tumors of very low incidence that affect adults. ${ }^{2}$ We found only two cases of solitary nasal trichoepitheliomas in the literature. ${ }^{3,4}$

The multiple and solitary forms are morphologically identical; they may be differentiated by the number of lesions ${ }^{2,3}$ These tumors are firm, translucent nodules or papules. ${ }^{5}$

The differential diagnosis of the solitary form is made mostly with the basocellular carcinoma, but also with the trichofoliculoma, melanocytic nevi and sebaceous hyperplasia. Histopathology provides the final diagnosis. ${ }^{1}$

Histologically, it is a well-differentiated tumor containing hair-forming structures and keratinous cysts surrounded by basophilic cells in an adenoid pattern.

Generally, surgical removal of the lesion for pathology is curative. In 1999, Jemec et $a .^{5}$ reviewed the first ten cases of the literature and found a recurrence in only one case after surgical removal.

\section{FINAL COMMENTS}

Solitary trichoepitheliomas are extremely rare benign tumors that should be considered when finding a single solid nodule or papula on the face. Confirmation by excision biopsy is essential for the diagnosis and treatment.

\section{REFERENCES}

1.Boni R, Fogt F, Vortmeyer AO, Tronic BS, Zhuang Z. Genetic analysis of a trichoepithelioma and associated basal cell carcinoma. Arch Dermatol 1998;134(9):1170-1.

2.Filho GB, Toppa NH, Miranda D, Matos MP, Silva AL. Giant solitary trichoepithelioma. Arch Dermatol 1984;120:797-8.

3.Dvir E. Solitary trichoepithelioma in a 70-yearold man. Arch Dermatol 1981;117:455-6.

4.Riberti C, Vaienti L, Parodi PC, Azzolini C. [A nasal reconstruction via the expansion of the tissue] [Article in Italian]. Acta Otorhinolaryngol Ital 1993;13(5):407-22.

5.Jemec B, Lovgreen Nielsen P, Jemec GB, Balsev E. Giant solitary trichoepithelioma. Dermatol Online J 1999;5(1):1.

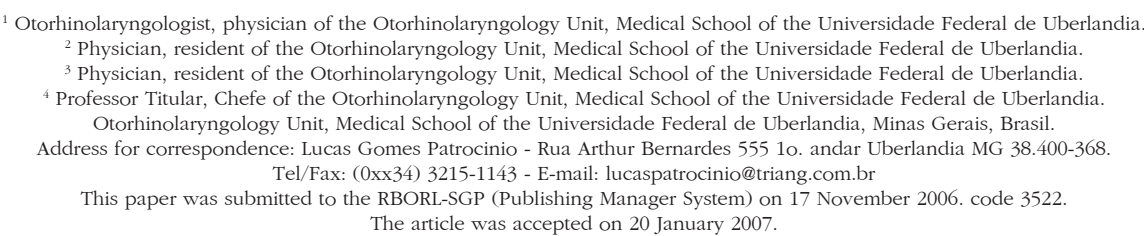

